\title{
Parametrization consequences of constraining soil organic matter models by total carbon and radiocarbon using long-term field data
}

\author{
Lorenzo Menichetti ${ }^{1}$, Thomas Kätterer ${ }^{2}$, and Jens Leifeld ${ }^{1}$ \\ ${ }^{1}$ Agroscope, Climate/Air Pollution Group, Reckenholzstrasse 191, 8046 Zürich, Switzerland \\ ${ }^{2}$ Department of Ecology, Swedish University of Agricultural Sciences (SLU), P.O. Box 7044, 75007 Uppsala, Sweden \\ Correspondence to: L. Menichetti (ilmenichetti@gmail.com)
}

Received: 8 December 2015 - Published in Biogeosciences Discuss.: 18 January 2016

Revised: 28 April 2016 - Accepted: 6 May 2016 - Published: 23 May 2016

\begin{abstract}
Soil organic carbon (SOC) dynamics result from different interacting processes and controls on spatial scales from sub-aggregate to pedon to the whole ecosystem. These complex dynamics are translated into models as abundant degrees of freedom. This high number of not directly measurable variables and, on the other hand, very limited data at disposal result in equifinality and parameter uncertainty.

Carbon radioisotope measurements are a proxy for SOC age both at annual to decadal (bomb peak based) and centennial to millennial timescales (radio decay based), and thus can be used in addition to total organic $\mathrm{C}$ for constraining SOC models. By considering this additional information, uncertainties in model structure and parameters may be reduced.

To test this hypothesis we studied SOC dynamics and their defining kinetic parameters in the Zürich Organic Fertilization Experiment (ZOFE) experiment, a >60-year-old controlled cropland experiment in Switzerland, by utilizing $\mathrm{SOC}$ and $\mathrm{SO}^{14} \mathrm{C}$ time series. To represent different processes we applied five model structures, all stemming from a simple mother model (Introductory Carbon Balance Model ICBM): (I) two decomposing pools, (II) an inert pool added, (III) three decomposing pools, (IV) two decomposing pools with a substrate control feedback on decomposition, (V) as IV but with also an inert pool. These structures were extended to explicitly represent total SOC and ${ }^{14} \mathrm{C}$ pools.

The use of different model structures allowed us to explore model structural uncertainty and the impact of ${ }^{14} \mathrm{C}$ on kinetic parameters. We considered parameter uncertainty by calibrating in a formal Bayesian framework.

By varying the relative importance of total SOC and $\mathrm{SO}^{14} \mathrm{C}$ data in the calibration, we could quantify the effect
\end{abstract}

of the information from these two data streams on estimated model parameters. The weighing of the two data streams was crucial for determining model outcomes, and we suggest including it in future modeling efforts whenever $\mathrm{SO}^{14} \mathrm{C}$ data are available.

The measurements and all model structures indicated a dramatic decline in SOC in the ZOFE experiment after an initial land use change in 1949 from grass- to cropland, followed by a constant but smaller decline. According to all structures, the three treatments (control, mineral fertilizer, farmyard manure) we considered were still far from equilibrium. The estimates of mean residence time (MRT) of the $\mathrm{C}$ pools defined by our models were sensitive to the consideration of the $\mathrm{SO}^{14} \mathrm{C}$ data stream. Model structure had a smaller effect on estimated MRT, which ranged between $5.9 \pm 0.1$ and $4.2 \pm 0.1$ years and $78.9 \pm 0.1$ and $98.9 \pm 0.1$ years for young and old pools, respectively, for structures without substrate interactions.

The simplest model structure performed the best according to information criteria, validating the idea that we still lack data for mechanistic SOC models. Although we could not exclude any of the considered processes possibly involved in SOC decomposition, it was not possible to discriminate their relative importance.

\section{Introduction}

The dynamics of soil organic carbon (SOC) are directly linked to major soil ecosystem services such as soil fertility, resistance to erosion, $\mathrm{C}$ sequestration, and soil $\mathrm{CO}_{2}$ emissions (Lal, 2004). Understanding such dynamics is therefore 
of paramount importance for the challenges of the present century (IPCC, 2014). In particular, the precise quantification of SOC cycles would allow for a monetization of the respective ecosystem services, and is a crucial step to overcome the failure of this market (Alexander et al., 2015).

However, the timescale of SOC decomposition, from years to millennia, makes it difficult to design experiments, and requires gathering indirect answers through analysis of monitoring programs, long-term experiments and SOC turnover models. Most of these models, for example among the most well-known RothC (Coleman et al., 1997), Century (Parton et al., 1993) and Yasso (Liski et al., 2005), are built around multiple conceptual pools decomposing with first-order kinetics. This basic structure works well to simulate decadal to centennial timescales, but shows problems with longer (when considering more protected organic matter; e.g., Trumbore and Czimczik, 2008) or shorter (when considering microbial dynamics; e.g., Schimel and Weintraub, 2003) timescales.

Formally, these models could be extended in complexity to represent more accurately all the processes involved in SOC decomposition that we are aware of. However, a purely mechanistic modeling approach often fails because the lack of data with respect to the complexity of the system limits the number of latent variables (all the variables that cannot be directly measured) that we can infer. A high system complexity, as characterized by multiple interactions between parameters, causes equifinality problems (Beven, 2006). Representing such interactions in a way that is both accurate and abstract enough to realistically consider the availability of data is termed the bias/variance dilemma (Briscoe and Feldman, 2011). This dilemma represents the most critical point in producing reliable estimates in SOC modeling.

The struggle of contemporary SOC models becomes more evident when including $\mathrm{SO}^{14} \mathrm{C}$ data. When time series for both total $\mathrm{SOC}$ and $\mathrm{SO}^{14} \mathrm{C}$ are available, they may suggest contradictory dynamics (Shirato et al., 2013). This confirms the high uncertainty in defining contemporary SOC model structures and at the same time raises the question of how to use these two sources of information.

Methods for the inclusion of radiocarbon measurements in SOC models are currently under active development. While most SOC models consider ${ }^{14} \mathrm{C}$ implicitly through the use of mass balance equations, some attempts have been made to consider ${ }^{14} \mathrm{C}$ explicitly (Ahrens et al., 2014) as a separate set of $\mathrm{C}$ molecules. A similar approach also has been proposed for ${ }^{13} \mathrm{C}$ by Ågren et al. (1996). The explicit approach offers more flexibility in the representation of processes that might influence $\mathrm{SO}^{14} \mathrm{C}$ at the price of a minimal increase in model complexity. Nevertheless, even with explicit consideration of ${ }^{14} \mathrm{C}$, modeling results are still not well determined (Ahrens et al., 2014).

Yet a few studies have considered $\mathrm{SO}^{14} \mathrm{C}$ data within an uncertainty analysis framework. Braakhekke et al. (2014) and Ahrens et al. (2014) both considered model uncertainty, but focused on a single model structure. However, both pa- rameter uncertainty and structural uncertainty are significant problems endemic to environmental models (Beven, 2002). Moreover, in both these studies the model sensitivity to radiocarbon was limited to two cases, either including or excluding $\mathrm{SO}^{14} \mathrm{C}$ data. The inclusion of $\mathrm{SO}^{14} \mathrm{C}$ data can modify the model space substantially (Ahrens et al., 2014) and in a non-linear way. The weight assigned to $\mathrm{SO}^{14} \mathrm{C}$ and $\mathrm{SOC}$ is a crucial parameter influencing strongly the modeling results, and the effect of this parameter should, therefore, be studied more in detail.

In order to consider the effect of ${ }^{14} \mathrm{C}$ data with respect to structural uncertainty, we calibrated a set of SOC models over total SOC time series from the Zürich Organic Fertilization Experiment (ZOFE) long-term field experiment (Oberholzer et al., 2014). In addition, we made use of $\mathrm{SO}^{14} \mathrm{C}$ measurements in key positions of the time series. Model structures were built around Introductory Carbon Balance Model (ICBM), a basic two-pool SOC decomposition model (Andrén and Kätterer, 1997), and calibrated within a Markov chain Monte Carlo framework to take care of equifinality and parameter uncertainty. We considered the possibility of substrate interactions by introducing a control term on decomposition influenced by the amount of fresh substrate available. To consider the effect of total SOC and $\mathrm{SO}^{14} \mathrm{C}$ on the calibration, we assigned a relative weight to the two data streams and calibrated model structures across a gradient of such weights.

The three research questions driving this work are the following:

- How will the inclusion of ${ }^{14} \mathrm{C}$ data influence the SOC parameters estimated from a multi-pool model?

- What are the reasons for the observed discrepancy between modeled total SOC and $\mathrm{SO}^{14} \mathrm{C}$ dynamics, and which are the most important ones?

- Can we model SOC and $\mathrm{SO}^{14} \mathrm{C}$ jointly in a way that is minimalist and flexible and yet effective?

These research questions generated the following, partially concurrent, hypotheses:

1. An underestimation of the age of slow $\mathrm{C}$ due to the presence of recalcitrant C (e.g., black C, Leifeld, 2008) or C protected through some other mechanisms is one possible reason for the observed discrepancy between SOC and $\mathrm{SO}^{14} \mathrm{C}$ modeled kinetics. Thus, representing such slow $\mathrm{C}$ in the model as inert or particularly slow pool will improve model performances.

2. An interaction between substrate pools is a process often neglected in $\mathrm{C}$ models but which can contribute the observed discrepancy. Representing this process in the model can improve model performances.

3. Is it possible to discriminate between the abovementioned processes? 
To answer our questions we compared the results from different model structures, each focusing on slightly different processes. By comparing different model structures we also aimed at understanding more realistically SOC kinetics in the ZOFE experiments by acknowledging some model structural uncertainty.

\section{Material and methods}

\subsection{Experimental site}

The data utilized in this study have been collected in the ZOFE (Oberholzer et al., 2014), located in Switzerland at the Agroscope premises in Reckenholz (Zürich), at $47^{\circ} 25^{\prime} 37^{\prime \prime} \mathrm{N}$, $8^{\circ} 31^{\prime} 6^{\prime \prime} \mathrm{E}$. The experiment was initiated in 1949 and comprises 12 different fertilization treatments, among which we selected three (Table 1): the control treatment (not receiving any fertilizer input), the mineral fertilization treatment (receiving yearly $139 \mathrm{~N}, 28 \mathrm{P}, 167 \mathrm{~K}, 56 \mathrm{~kg} \mathrm{ha}^{-1}$ since 1981 and $108 \mathrm{~N}, 61 \mathrm{P}, 318 \mathrm{~K}, 12 \mathrm{~kg} \mathrm{ha}^{-1}$ in the period 1949-1980) and the farmyard manure (FYM) treatment (receiving yearly $91 \mathrm{~N}, 24 \mathrm{P}, 65 \mathrm{~K}, 31 \mathrm{~kg} \mathrm{ha}^{-1}$ from organic fertilizer and, biannually, $1 \mathrm{Mg}$ organic carbon from FYM). The site was lowintensity permanent grassland before 1949. The experiment is ploughed to an approximate depth of $25 \mathrm{~cm}$, and therefore we considered for all the subsequent analyses only the portion 0-25 cm. Soil is a Luvisol (WRB, 2007), carbonate-free, with $14 \%$ clay, $27 \%$ silt and $57 \%$ sand. Organic C content was $1.3 \%$ at the beginning of the experiment, and soil $\mathrm{pH}$ $\left(\mathrm{H}_{2} \mathrm{O}\right)$ was 6.5 . The crop rotation has a period of 8 years, and includes winter wheat/intercrop, maize, potatoes, winter wheat/intercrop, maize, summer barley, ley, and ley. Main products and aboveground parts of by-products of crops were always removed. Belowground residues, for example in the case of beetroots or potatoes, where incorporated into the soil as were roots.

\subsection{Data collection and soil analyses}

The SOC data set comes from Oberholzer et al. (2014). For modeling, the calibration error for both $\mathrm{SOC}$ and $\mathrm{SO}^{14} \mathrm{C}$ has been expressed as coefficient of variation $(\mathrm{CV})$. The $\mathrm{CV}$ of the SOC measurements has been measured independently in 2012 (data not published) and varied between 0.080 and 0.086 for the different treatments. The $\mathrm{SO}^{14} \mathrm{C}$ data set comes from Leifeld and Mayer (2015). The CV in 2012 varied in this case between 0.017 and 0.029 , and has been extrapolated to the whole $\mathrm{SO}^{14} \mathrm{C}$ time series. All radiocarbon concentrations utilized here are expressed in percent of modern carbon (pMC) as described in Stuiver and Polach (1977).

In the $\mathrm{SO}^{14} \mathrm{C}$ time series we assumed that the pre-bomb $\mathrm{SOC}$ was at equilibrium with the atmospheric isotopic value. Although the $\mathrm{SO}^{14} \mathrm{C}$ might slightly deviate from the ${ }^{14} \mathrm{C}$ content of the atmosphere, the difference between any possible natural discrimination and the effect of the bomb peak is sev- eral orders of magnitude (Goslar et al., 2004) and we regard such a difference as negligible. In order to improve the calibration of the model with respect to the $\mathrm{SO}^{14} \mathrm{C}$ trend, we assumed a fourth $\mathrm{SO}^{14} \mathrm{C}$ point in year 1955 as corresponding to the atmospheric signature. All the time series referring to ZOFE are unevenly spaced, as often the case with multidecadal experiments.

We took the atmospheric ${ }^{14} \mathrm{C}$ time series from the Schauinsland station (Levin and Kromer, 2004; Levin et al., 2013), relatively close to our site $(48 \mathrm{~km})$. Radiocarbon values from May to August are commonly used to represent the vegetation's signature (Levin and Kromer, 2004), but this implies the assumption of $\mathrm{CO}_{2}$ fixation only in late spring-summer. We calculated the difference in the time series with and without filtering out autumn-winter months, after a spline interpolation to regularize the time series, as $3.4 \mathrm{pMC}$ (root mean squared error, RMSE), representing a $\mathrm{CV}$ between 0.01 and 0.03 . This we considered as negligible and used yearly averages instead.

\subsection{Calculation of $\mathrm{C}$ inputs}

The $\mathrm{C}$ inputs have been calculated with the $\mathrm{C}$ allocation coefficients proposed by Bolinder et al. (2007) and in case of potatoes by Walther et al. (1994). More details about the input calculations can be found in Oberholzer et al. (2014).

Carbon allocation coefficients may differ between treatments. The potential error introduced by the nonlinear nature of the root/shoot factor (Bond-Lamberty et al., 2002) was considered negligible in our case due to conditions being close to optimal for plant growth at our site. The control treatment still stores as much SOC as treatments with full mineral fertilization (Oberholzer et al., 2014) and it was still considered to be far from causing extreme deviations from the selected root/shoot ratio. Another source of error in our estimate is inherent to extrapolating the original root-shoot relationship (Bolinder et al., 2007) to our soil. Such a relationship was built on 168 samples reviewed from the literature of typical agricultural soils, not different from our alluvial soil, and this error should therefore be small. Another possible error comes from the lack of estimates for $\mathrm{C}$ in the form of root exudates.

We considered the above uncertainties for the $\mathrm{C}$ allocation by introducing an error factor calibrated with a uniform prior distribution between 0.8 and 1.2.

\subsection{Five possible model structures for SOC}

The basic model (structure I) is the ICBM model developed by Andrén and Kätterer (1997). ICBM is a minimalist model of the general SOC decomposition theory built around two SOC pools decomposing with first-order kinetics. The simplicity of the model allows for a high degree of flexibility and makes it ideal for model structure explorations, hypotheses testing, and model development. 
Table 1. The treatments considered in this study.

\begin{tabular}{|c|c|c|c|c|c|c|c|c|}
\hline \multirow[t]{2}{*}{ Treatment } & \multicolumn{6}{|c|}{ Annual input } & \multirow[t]{2}{*}{ Initial SOC ${ }^{2}$} & \multirow[t]{2}{*}{ Final SOC $^{2}$} \\
\hline & $\mathrm{N}^{1}$ & $\mathrm{P}^{1}$ & $\mathrm{~K}^{1}$ & $\mathrm{Mg}^{1}$ & $\begin{array}{r}\text { Fertilizer } \\
\mathrm{C}^{1}\end{array}$ & $\begin{array}{r}\text { Estimated } \\
\text { total } C^{1}\end{array}$ & & \\
\hline Control & 0 & 0 & 0 & 0 & 0 & 580 & 38.75 & 24.28 \\
\hline $\mathrm{N}_{2} \mathrm{P}_{2} \mathrm{~K}_{2} \mathrm{Mg}$ & $108^{a} / 139^{b}$ & $61^{c} / 38^{d}$ & $318^{\mathrm{c}} / 167^{\mathrm{d}}$ & $12^{\mathrm{a}} / 56^{\mathrm{b}}$ & 0 & 1350 & 38.75 & 27.05 \\
\hline Farmyard manure & $91^{3}$ & $24^{3}$ & $65^{3}$ & 31 & 2500 & 3621 & 38.75 & 31.70 \\
\hline
\end{tabular}

${ }^{1} \mathrm{~kg} \mathrm{ha}^{-1}$ years ${ }^{-1},{ }^{2} \mathrm{Mg} \mathrm{ha}^{-1},{ }^{3}$ from organic amendment. ${ }^{\mathrm{a}} 1949-1980,{ }^{\mathrm{b}}$ since $1981,{ }^{\mathrm{c}} 1949-1990,{ }^{\mathrm{d}}$ since 1991 . All soil values refer to $0-25 \mathrm{~cm}$ depth interval.

We used the model stepwise in its recursive form, as derived by Kätterer et al. (2004), in order to follow the highly nonlinear shape of the atmospheric ${ }^{14} \mathrm{C}$ curve of the last century (Kurths et al., 1994). The dynamic system representing SOC is described by the following equations:

$$
\begin{aligned}
& Y_{(t)}=\left(Y_{(t-1)}+i_{(t-1)}\right) e^{-k_{Y} r}, \\
& O_{(t)}=\left(O_{(t-1)}+\varphi_{Y(t-1)}\right) e^{-k_{O} r}+\varphi_{Y_{(t-1)}} e^{-k_{Y} r}, \\
& \varphi_{Y_{(t-1)}}=h_{1} \frac{k_{Y}\left(Y_{(t)}+i_{(t)}\right)}{k_{O}+k_{Y}} .
\end{aligned}
$$

The SOC at time $t$ is therefore calculated as

$\operatorname{Tot}_{(t)=} Y_{(t)+} O_{(t)}$.

This system describes the evolution of two $\mathrm{C}$ pools, young $(\mathrm{Y})$ and old $(\mathrm{O})$ SOC, decomposing with rate $k_{Y}$ and $k_{O}$. Their mean residence time (MRT) is defined by the reciprocal of the decomposition constants, or $\frac{1}{k_{Y}}$ and $\frac{1}{k_{O}}$. The term $i$ represents the inputs. The term $\varphi$ describes the flux between the two pools, which is controlled by the humification coefficient $h_{1}$ that defines the amount of carbon that goes from $\mathrm{Y}$ to $\mathrm{O}$. The term $r$ aggregates climatic and edaphic influence, and is calculated according to equations that follow in the text. The system of Eqs. (1), (2), (3), and (4) can then be modified in order to represent different hypotheses. The model defined by the system of Eqs. (1), (2), (3), and (4) is therefore calibrated for four unknown parameters, namely $k_{Y}, k_{O}, h_{1}$, and the initial distribution of $\mathrm{C}$ between pools $\mathrm{Y}$ and $\mathrm{O}$.

A first modification (i.e., model structure II), already suggested by Juston (2012), adds a static pool representing SOC cycling at extremely slow decomposition rates. This pool is virtually inert and does not interact with the other pools or decomposes. Since the SOC age spectrum is likely distributed according to a logarithmic function of age (Bosatta and Agren, 1999), this approximation may be reasonable for very slow SOC atoms. Equation (4) can therefore be modified by adding an "inert" pool $R$ as

$\operatorname{Tot}_{(t)=} Y_{(t)+} O_{(t)}+R$

This modification adds one parameter to the initial calibration to represent the initial value of $R$.
A second modification, i.e., model structure III, introduces a decomposing third pool instead of a static third pool. The dynamics of the $R$ pool in Eq. (5) now are similar to $\mathrm{O}$ in Eq. (2):

$$
\begin{aligned}
& R_{(t)}=\left(R_{(t-1)}+\varphi_{O_{(t-1)}}\right) e^{-k_{R} r}+\varphi_{O_{(t-1)}} e^{-k_{O} r}, \\
& \varphi_{O_{(t-1)}}=h_{2} \frac{k_{O}\left(O_{(t)}+\varphi_{Y_{(t)}}\right)}{k_{R}+k_{O}} .
\end{aligned}
$$

This modification adds two more unknown parameters to the initial model, namely $k_{R}$ and $h_{2}$ (Table 2).

A third modification of structure I, i.e., model structure IV, modifies the basic set of equations with a single, aggregated term to account for the effect of "young" substrates on microbial dynamics and therefore on decomposition rates. We modified Eqs. (1) and (2) by adding the term $\alpha$ in the exponent of the decomposition function according to Wutzler and Reichstein (2013). Since the fluxes from the slower and older pools are small compared to the flux from the younger pool we approximated the system by neglecting the former in calculating $\alpha$ as already suggested by Wutzler and Reichstein (2013). The resulting equation defining $\alpha$ is

$\alpha=\max \left(0,1-\frac{\beta}{h k_{Y}\left(Y_{(t)}+i_{(t)}\right)}\right)$,

where $\beta$ represents a lumped term aggregating microbial limitations on decomposition (Wutzler and Reichstein, 2013). The term $\alpha$ is introduced as a modifier for both $k_{Y}$ and $k_{O}$. The denominator represents the maximum possible microbial uptake, which is the total flux from $\mathrm{Y}$ to $\mathrm{O}$. When the flux from the young pool is below the value of $\beta$, decomposition goes to zero, but when this flux increases above this value decomposition approaches $k_{Y}$ and $k_{O}$.

This model structure adds one more unknown parameter (Table 2). Finally, model structure II was extended by a substrate control as in structure IV to make structure V. All model structures were run in annual time steps.

For model structures III and IV, with a substrate interaction term, an alternative MRT could be defined as $\frac{1}{k \times \alpha}$. Although, since its discussion goes beyond the scope of this manuscript, we did not consider such a definition for our results, we reported it in order to better explain the numerical effect of Eq. (8) on MRT. 
Table 2. Summary of the model structures tested in this study (considered here in their basic forms for total C only and for the two isotopes together).

\begin{tabular}{lrrrrr}
\hline & Structure I & Structure II & Structure III & Structure IV & Struct. V \\
\hline Description & $\begin{array}{r}\text { Two } \\
\text { pools }\end{array}$ & $\begin{array}{r}\text { Two } \\
\text { pools }+ \text { inert }\end{array}$ & $\begin{array}{r}\text { Three } \\
\text { pools }\end{array}$ & $\begin{array}{r}\text { Two pools }+ \\
\text { substrate } \\
\text { control }\end{array}$ & $\begin{array}{r}\text { Two pools }+ \\
\text { substrate } \\
\text { control + inert }\end{array}$ \\
\hline $\begin{array}{l}\text { Parameters } \\
(\mathrm{SOC})\end{array}$ & 4 & 5 & 7 & 5 & 6 \\
$\begin{array}{l}\text { Parameters } \\
\left(\mathrm{SOC}+\mathrm{SO}^{14} \mathrm{C}\right)\end{array}$ & $4+1$ & $5+2$ & $7+3$ & $5+1$ & $6+2$ \\
\hline
\end{tabular}

\subsection{Model structure for $\mathrm{SO}^{14} \mathrm{C}$}

Each model structure was extended by running a separate system of equations for $\mathrm{SO}^{14} \mathrm{C}$. With the introduction of $\mathrm{SO}^{14} \mathrm{C}$, the number of parameters increases (Table 2). We calculated the ratio of ${ }^{12} \mathrm{C} /{ }^{14} \mathrm{C}$ from the pMC value according to the definitions given in Stuiver and Polach (1977), and calculated from this ratio the mass of ${ }^{14} \mathrm{C}$. We set the $\delta^{13} \mathrm{C}$ normalization factor at $-26 \%$, close to that of a typical $\mathrm{C} 3$ soil. Most parameters were assumed to be the same as for SOC except for the initial distribution of the $\mathrm{SO}^{14} \mathrm{C}$ pools, which was allowed to vary by using a normal prior distribution centered on the mean of SOC pools distribution and with a coefficient of variation of 0.1 .

The radiocarbon decay is considered by adding the term $\lambda$, corresponding to $\frac{1}{8265}$ years $^{-1}$ (Stuiver and Polach, 1977), to all decomposition constants that then become $k_{\text {pool }}+\lambda$.

We did not consider a time lag between $\mathrm{C}$ assimilation and release into the SOC cycle because we are considering an agricultural system with annual plants. These plants have a physiological time lag of few hours (Kuzyakov and Gavrichkova, 2010) and eventual storage compounds are released at the end of the cultural cycle, which is in most cases less than 1 year. The years during rotation where leys are present are few (Oberholzer et al., 2014). With the annual resolution utilized in this study the time lag could therefore considered being negligible.

The effect of the two data streams (SOC and $\mathrm{SO}^{14} \mathrm{C}$ ) on the calibration of the model structures has been tested by introducing an arbitrary weighting term. This value, between 0 and 1, acts in the Bayesian calibration to modify the variance of the probability distributions representing the two time series. When the weighting term tends to 1 , the variance defining the SOC probability distribution tends to 0 while for the $\mathrm{SO}^{14} \mathrm{C}$ probability distribution it tends to infinite (Supplement Fig. S1). This alters the weight of that particular time series on the joint posterior distribution of the calibrated values. The precision of the $\mathrm{SO}^{14} \mathrm{C}$ data stream tends to zero and so it does not influence the calibration. When the weighting tends to zero, the opposite applies.
In order to better capture the effect of adding the information contained in the $\mathrm{SO}^{14} \mathrm{C}$ data stream in the calibration, we run all the calibrations over a gradient of such weights (with discrete values $0.05,0.175,0.350,0.500,0.650,0.825$, 0.950).

Since the two data streams are not homogeneous, this weighting term is considered as an empirical evaluation of the sensitivity of the model. It is an effective method for assessing the relative effect of the information from either isotope and offers more detail compared to testing only for the two options (SOC only and $\mathrm{SOC}+\mathrm{SO}^{14} \mathrm{C}$ ) separately.

\subsection{Considering kinetic isotope effects in soil}

A possible differential loss of $\mathrm{SO}^{14} \mathrm{C}$ compared to $\mathrm{SOC}$, caused by kinetic isotope effects (Tsai and $\mathrm{Hu}, 2013$ ), is accounted for by the standard normalization of ${ }^{14} \mathrm{C}$ values for $\delta^{13} \mathrm{C}$. Since every process that possibly causes a variation of the ${ }^{13} \mathrm{C}$ content from the moment that the $\mathrm{CO}_{2}$ was fixed might be assumed squared on ${ }^{14} \mathrm{C}$ (Stuiver and Polach, 1977), the normalization considers any process that can influence the $\mathrm{C}$ signature. This normalization relies on the assumption that the ${ }^{13} \mathrm{C} /{ }^{14} \mathrm{C}$ ratio in nature is stable, since every molecule originates from atmospheric $\mathrm{CO}_{2}$, which is supposedly homogeneous in open air. The Suess effect, a change in the atmospheric isotopic composition triggered by the burning of fossil fuels (e.g., Francey et al., 1999), does not represent in this sense a problem since the ${ }^{14} \mathrm{C}$ values are calibrated over atmospheric time series. Errors in the correction might be introduced by eventual local hot spots (e.g., industrial contaminations) for the atmospheric ${ }^{13} \mathrm{C} /{ }^{14} \mathrm{C}$ ratio. Our site, located at few kilometers from any major industry and hundreds of meters from any building, should be relatively free from local contamination sources and the closeness of the site to the measurement of atmospheric ${ }^{14} \mathrm{C}$ time series should account for regional variations. Nevertheless, we considered the possible error associated with these assumptions by allowing the initial ratios of the ${ }^{14} \mathrm{C}$ pools to vary slightly for ${ }^{14} \mathrm{C}$ by assigning a normal prior distribution to them, centered on the SOC ratios with deviation corresponding to $1 \%$ of these values. 


\subsection{Climatic and edaphic variables}

The parameter $r$ in Eqs. (1) and (2) in the original ICBM calibration (Andrén and Kätterer, 1997) aggregates all the influences on SOC from soil type and climate. It was originally conceived as a constant, but it also has been used as a response variable connected with climatic and edaphic factors (Andrén et al., 2012). We decided to consider $r$ according to the following equation:

$r_{(t)}=r_{\operatorname{Temp}(t)} \times r_{\operatorname{Moist}(t)} \times \varepsilon$,

where $r_{\text {Temp }}$ and $r_{\text {Moist }}$ are the decomposition rate modifiers due to temperature and soil moisture, respectively, and $\varepsilon$ is an error term.

In this particular case we included proxies for soil temperature and soil moisture and we selected the two climatic functions from the CENTURY model (Parton et al., 2001; Bauer et al., 2008), since they adapted well to the data available for this experiment. The temperature function was adopted as follows:

$r_{\text {Temp }}(t)=0.56+0.465$

$$
\times \arctan (0.097 \times(T-15.7))
$$

while the moisture function was adopted as follows:

$r_{\text {Moist }}(\theta)=\left(1+30 e^{\left(\frac{-8.5 \times P P T}{P E T}\right)}\right)^{-1}$,

where $T$ is soil temperature $\left({ }^{\circ} \mathrm{C}\right), P P T$ is the sum of stored water and precipitation, in our case approximated to total accumulated precipitation for the reference period due to the nature of our data set, and PET is the potential evapotranspiration (Primault, 1962). The term $\varepsilon$ has been described with a uniform distribution between -0.5 and +0.5 .

Meteorological data were obtained from the Swiss Federal Research Station for Agroecology and Agriculture ZürichReckenholz (FAL), located at less than $100 \mathrm{~m}$ from the ZOFE experiment.

In order to maintain comparability of results with the original ICBM model, $r$ has been normalized with its mean value as $r_{\text {norm }(t)}=\frac{r_{(t)}}{r}$, therefore making it vary around 1 . The normalization, together with the introduction of the $\varepsilon$ term in Eq. (9), reconciles the climatic functions with ICBM. The resulting variation of the $r_{\text {norm }}$ term is pictured in Fig. S2. Since we are comparing three treatments in the same field, we do not need to take into account any difference in climate between the plots, and we can use the climatic parameter only to account for variability in the data that might be due to inter-annual climatic variation.

\subsection{Model calibration, initialization, and prior assumptions}

Given the close interactions between the kinetic parameters a deterministic optimization algorithm might miss possible equifinality (Beven, 2008). We therefore relied on a
Metropolis-Hastings algorithm (in the implementation of JAGS (Just Another Gibbs Sampler) Plummer, 2003). The likelihood function utilized was the default one in JAGS, which according to a formal Bayesian statistical framework utilizes a Gaussian shape.

We assumed that the parameters defining the SOC pools (namely, $k_{\text {pool }}, h_{\text {pool }}$, and the initial pool distribution) were the same for all treatments. Every calibration has been run in four separated Markov chains, and the convergence of the chains has been assessed visually through the use of Gelman's plots (Brooks and Gelman, 1998). Each chain was calibrated with a first adaptation period of 10000 runs of which 5000 have been discarded as burn-in period, and then 100000 search runs. The chains always showed reasonable convergence.

Priors for the rates $\left(k_{\mathrm{pool}}\right)$ have been considered as normally distributed, with mean value coming from Andrén and Kätterer (1997) and deviation set to half of the mean value. The mean of the prior for $k_{O}$ has been set considering it as a fixed ratio of the value of $k_{Y}$. This ratio (0.075) also has been calculated from Andrén and Kätterer (1997). The priors for $h_{Y}$ have been considered normally distributed. Mean values to represent the different input qualities were calculated as averages of all the scenarios reported in Kätterer et al. (2011) as follows. By assuming the composition of the young pool being similar to the inputs, we chose the prior value for $h_{Y}$ for the control and the mineral fertilizer treatments as 0.185 (which is the average for roots and shoots) while for the farmyard manure the chosen value was 0.265 . We have chosen for this parameter stronger prior distributions by setting its deviation to $10 \%$ of the mean value. In the third model structure the $h_{O}$ prior has been set as an uniform distribution between 0 and $h_{Y}$.

Priors for the initial distribution of the SOC pools were considered uniformly distributed between 0 and $100 \%$ of initial SOC but constrained by the mass balance, i.e., the sum of SOC mass in all pools should add up to $100 \%$ of initial SOC. Priors for the initial distribution of the pools for $\mathrm{SO}^{14} \mathrm{C}$ were generated with a uniform distribution using the portion of total SOC pools as mean and variance set to $1 \%$ of this value.

\subsection{Model comparison and selection}

Following the same principle of simplicity maximization on which we built the whole study, we selected the Akaike information criterion (AIC) to estimate the information content of the model structures. The AIC has been calculated as

$A I C=2 k+n \times \log \left(\frac{\mathrm{RSS}}{n}\right)$,

where $p$ is the number of parameters, $n$ is the number of samples, and RSS is the residual sum of square of the model.

The use of the RSS in Eq. (12) is a simplification, since it is a metric only proportional to the likelihood. The difference lies in the lack of one integration constant. Since the 


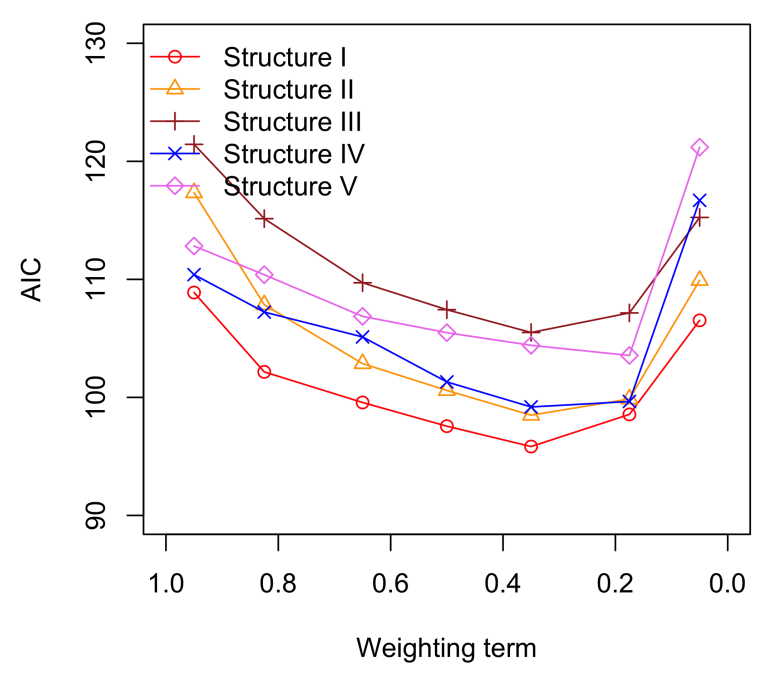

Figure 1. Average of the $A I C$ among all the three treatments for the five model structures with the variation of the relative weight of $\mathrm{SO}^{14} \mathrm{C}$ over total $\mathrm{C}$. In this scale 1 means only total $\mathrm{C}, 0$ means only $\mathrm{SO}^{14} \mathrm{C}$.

$A I C$ is used in this study only for a relative comparison between model structures, we considered this approximation justifiable. The use of the $A I C$ rather than RMSE for measuring model performances can capture how the different model structures react to the introduction of the additional stream of information, i.e., $\mathrm{SO}^{14} \mathrm{C}$, by acting as a structure-dependent normalization, allowing for a performance comparison between different structures. Also the best weighting parameter representing the partial weight of SOC and $\mathrm{SO}^{14} \mathrm{C}$ data has been selected according to the smallest AIC.

The choice of the AIC is motivated by its simplicity (explicit also in the intention of his author, Akaike, 1974), and by the consideration that we are comparing models over exactly the same number of samples (Burnham and Anderson, 2004). But since the choice of any model performance indicator is highly subjective, we also calculated for all the models the deviance information criterion (DIC; Plummer, 2008) for comparison with the $A I C$.

\section{Results}

\subsection{Effect of the SOC data stream on model performances}

In general the addition of the $\mathrm{SO}^{14} \mathrm{C}$ data always improved the performance of the calibrations until a certain optimal point. This effect was similar for any of the different model structures, and an eventual relative advantage of one structure above another in considering information from $\mathrm{SO}^{14} \mathrm{C}$ data was not evident. The improvement increased for every structure up to a partial weight of 0.35 , and then worsened marginally when moving forward toward a higher weight of

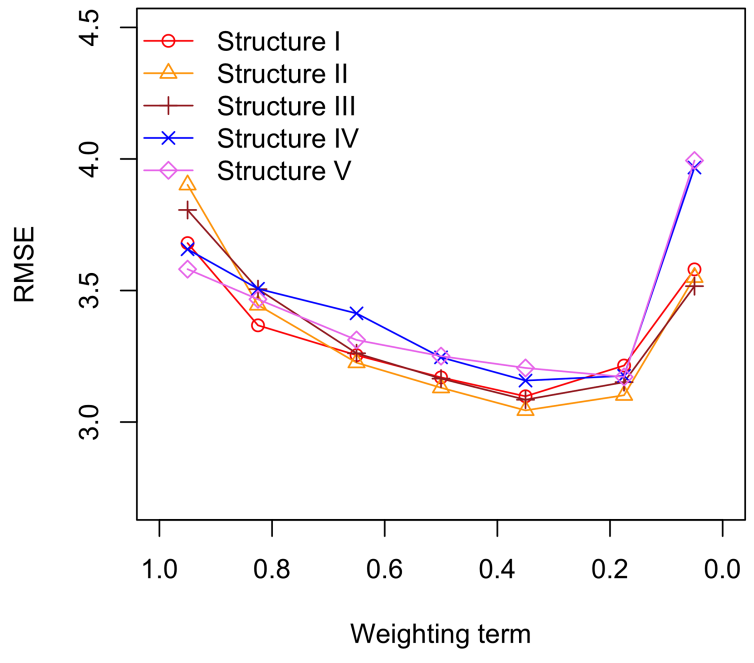

Figure 2. Average of the RMSE among all the three treatments for the five model structures with the variation of the relative weight of $\mathrm{SO}^{14} \mathrm{C}$ over total $\mathrm{C}$. In this scale 1 means only total $\mathrm{C}, 0$ means only $\mathrm{SO}^{14} \mathrm{C}$.

$\mathrm{SO}^{14} \mathrm{C}$ data (Fig. 1). However, the decrease in performances was dramatic when moving towards a bigger relative weight of $\mathrm{SO}^{14} \mathrm{C}$ data.

The introduction of the $\mathrm{SO}^{14} \mathrm{C}$ data stream in general decreased the uncertainty of the parameters until an optimal weight for all the models without a substrate interaction (structures I, II, and III), and the average coefficient of variation of the parameters followed a general pattern similar to the average AIC (Fig. S3). For the structures including substrate interaction (VI and V), the pattern was oscillating in a more complicated way, making it impossible to identify any consistent trend. The RMSE (Fig. 2) of the model structures was closely related to the AIC but with different relative values for the different structures.

\subsection{Optimal model choice}

Overall, the "best" model structure indicated by the $A I C$ to best describe our data was the basic ICBM, structure I (Fig. 1). This is particularly true for the FYM treatment (with highest SOC), which was the treatment best described by all our model structures.

The average RMSE was similar for all model structures, but there were small differences. Unexpectedly, structure III did not present the lowest average RMSE among all structures (Fig. 2), although it has the highest number of parameters. Structure II was the one that performed the best in terms of RMSE.

We also compared these five structures through DIC, which was $\mathbf{5 9 1 . 9}$ for structure I, $\mathbf{5 7 9 . 9}$ for structure II, 593.8 for structure III, 603.1 for structure IV, and 591.9 for structure V. Also the DIC indicated better performances of simpler structures and it indicated structure II as the best model. 
However, it did not indicate any difference between the second and third best choice (structure I and V) and differences were not as evident as when using AIC.

\subsection{SOC distribution and kinetics in the ZOFE experiment as estimated by different model structures}

The MRT (Fig. 3) of the old pool, according to structures I and II, were $95.09 \pm 0.1$ and $78.9 \pm 0.1$ years, respectively, while the ones for the young pool were $5.9 \pm 0.1$ and $5.3 \pm 0.1$ years. Owing to the introduction of an additional term, modifying the kinetic in relation to the amount of young substrate, the results differ for structures IV and V. Here, MRT results were $14.9 \pm 0.95$ and $16.8 \pm 0.5$ years for the old pool and $0.9 \pm 0.3$ and $1.0 \pm 0.3$ years for the young pool, respectively. Structure III determined pool definitions similar to structure I and II; and in this case the MRT was $98.9 \pm 0.10$ years for the old and $4.2 \pm 0.1$ years for the young pool. The third, "recalcitrant" pool in structure III revealed a MRT of $477.98 \pm 0.7$ years. Simulation results are shown only for structure I (Fig. 7) and II (Fig. 8), and for structure II, III and V in Figs. S5, S6 and S7.

The estimated size of the initial pools did not vary much among the selected model structures (Fig. 9). The amount of carbon in the young pool ranged from $15.37 \pm 1.64 \mathrm{Mg} \mathrm{ha}^{-1}$ (structure I) to $11.37 \pm 1.50 \mathrm{Mg} \mathrm{ha}^{-1}$ (structure III). The amount of carbon in the old pool ranged from $22.70 \pm 1.59 \mathrm{Mg} \mathrm{ha}^{-1}$ (structure I) to $20.28 \pm 1.74 \mathrm{Mg} \mathrm{ha}^{-1}$ (structure IV) for structures considering only two pools, while it ranged from $25.25 \pm 1.39 \mathrm{Mg} \mathrm{ha}^{-1}$ (structure II) to $23.00 \pm 1.70 \mathrm{Mg} \mathrm{ha}^{-1}$ (structure III) for structures considering three pools. As evident from Figs. 3, 4, and 5, these results are also strongly dependent on the choice of the weighting parameter between the $\mathrm{SOC}$ and the $\mathrm{SO}^{14} \mathrm{C}$ data streams.

All the tested model structures, and within all the tested values of the weighting parameter, inferred a change right after the land use change in the ZOFE trial. In all treatments without amendments, the young pool decreased rapidly within a few years after conversion from grassland to FYM and mineral fertilization. In structures I this decrease was more dramatic, while more complex models (II, III, IV, and V) could describe the observed trends as more gradual thanks to the additional number of parameters.

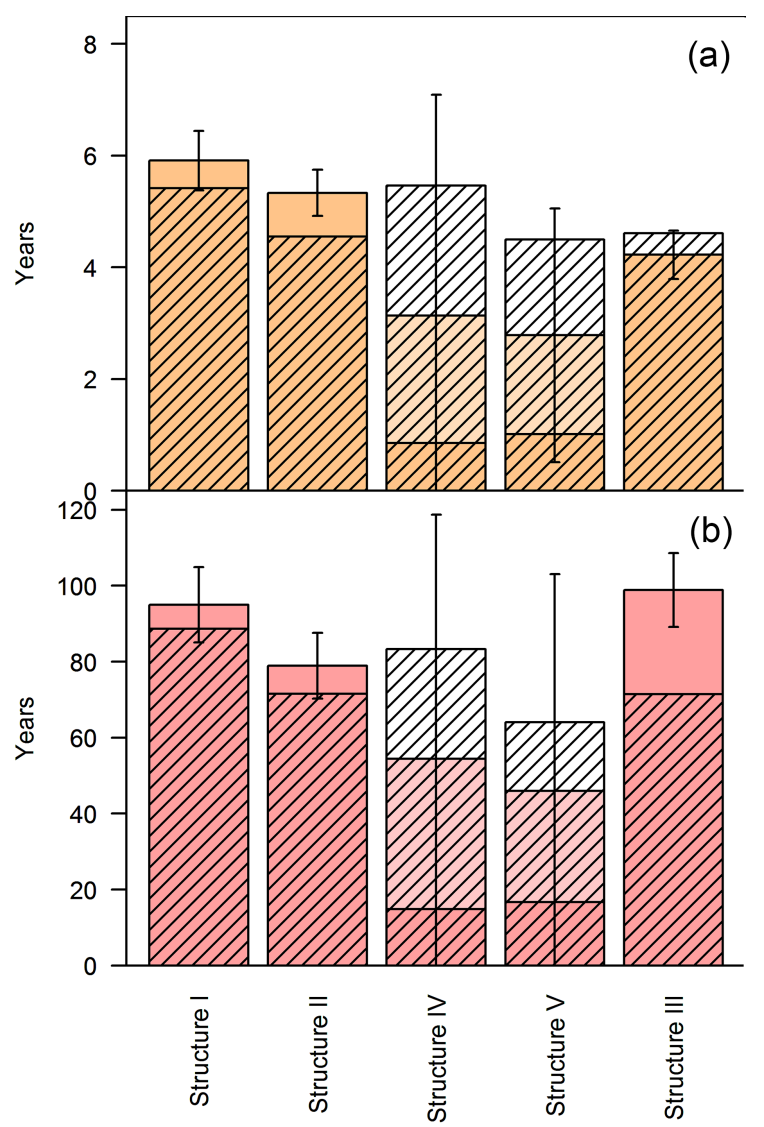

Figure 3. MRT of the young pool (a) and old pool (b) of SOC in the ZOFE trial as indicated by the model structures examined, with weighting factor $=0.35$ (solid colored area) and weighting factor $=0.65$ (shaded area). The solid lighter colored area denotes the MRT calculated (for structures IV and V) according to $\frac{1}{k \times \alpha}$, while the darker colored area according to $\frac{1}{k}$, Error bars, reported only for weighting factor $=0.35$ for readability reasons, denote the error of the estimate calculated as standard deviation of the whole Markov chain and depends on the model structure, model assumptions, and priors.

\subsection{Effect of the C data stream on the kinetics of SOC pools}

During calibration, all model structures seemed to react to the $\mathrm{SO}^{14} \mathrm{C}$ data by reducing decomposition rates and humification coefficients, i.e., the introduction of $\mathrm{SO}^{14} \mathrm{C}$ decelerated $\mathrm{C}$ turnover. For structure $\mathrm{I}$ the effect of adding the $\mathrm{SO}^{14} \mathrm{C}$ data seemed to slow down the decomposition of both pools (Fig. 4). This decrease was associated with a decrease of the humification coefficient, hence also reducing the flux of material that goes from a faster to a slower pool. At the same time, the relative size of the slower pool decreased. For structure IV (Fig. 4) the addition of a substrate interaction term made the decrease in speed of $\mathrm{C}$ cycling associated with the introduction of $\mathrm{SO}^{14} \mathrm{C}$ data more dramatic and in some specific cases more difficult to interpret, but in general, 

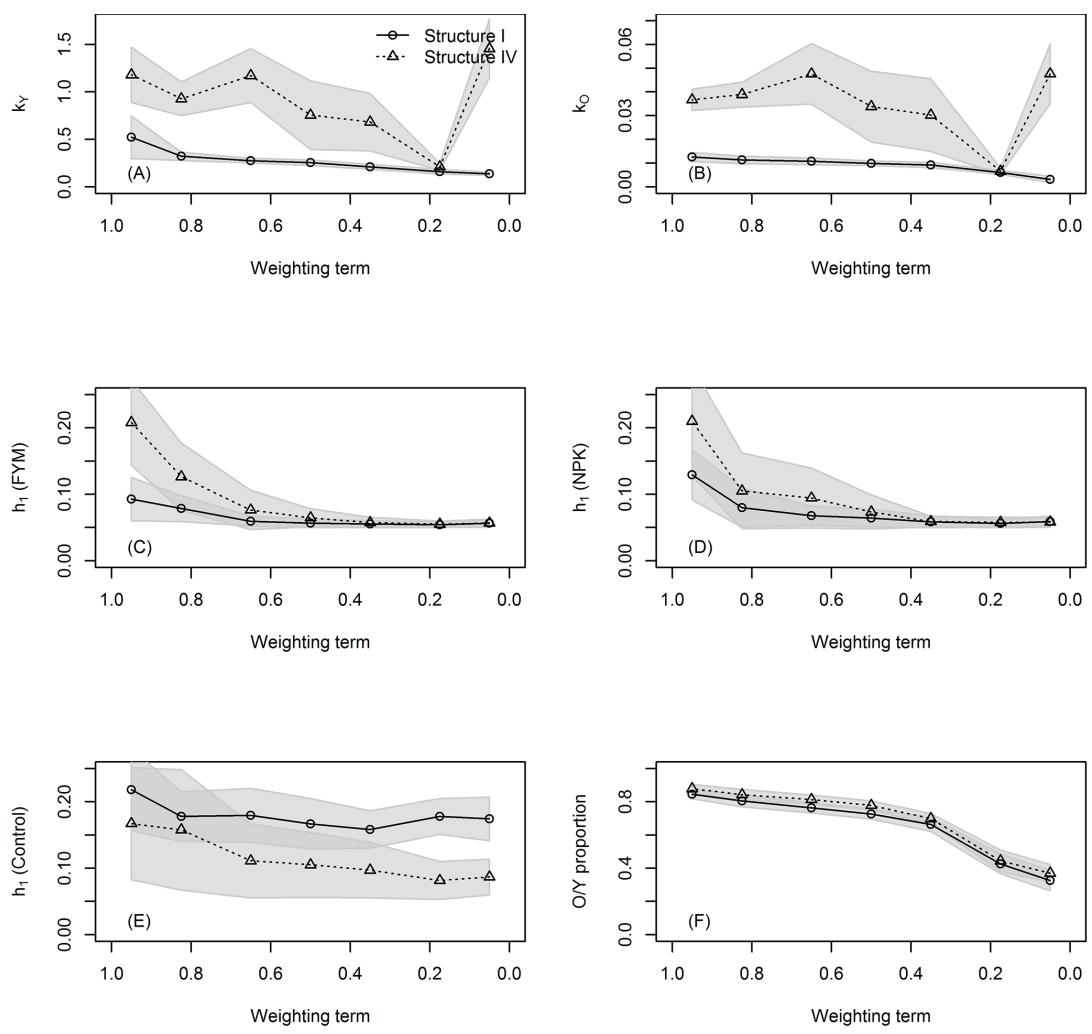

Figure 4. Effect of the $\mathrm{SO}^{14} \mathrm{C}$ stream over the main SOC parameters in structures I and IV. In this scale 1 means only total C, 0 means only $\mathrm{SO}^{14} \mathrm{C}$. Letters A to $\mathrm{F}$ denote subpanels referring to different parameters. The shaded areas represent the error of the calibrated parameter (calculated as standard deviation of the whole Markov chain).

the trend was similar. In structures with a third inert pool, II and V (Fig. 5), trends were replicating those with only two pools. Structure V presented a pattern very similar to structure IV. The inert pool proportion increased with the increase of the weight of $\mathrm{SO}^{14} \mathrm{C}$ data. Also results from structure III (Figs. S5, 6) indicate a consistent reduction in the speed of C cycling with the introduction of the $\mathrm{SO}^{14} \mathrm{C}$ data. In general we can affirm that the inclusion of the $\mathrm{SO}^{14} \mathrm{C}$ data decreased the size of the slower $\mathrm{O}$ pool while it increased the residence time of both $\mathrm{Y}$ and $\mathrm{O}$ pools.

\section{Discussion}

\subsection{Modeling the kinetics of SOC pools}

None of our tested model structures could represent consistently both data streams at the same time. For the $\mathrm{SO}^{14} \mathrm{C}$ value measured in 1973, every model structure underpredicted the isotopic value of SOC particularly for the low input treatment. Conversely, the last $\mathrm{SO}^{14} \mathrm{C}$ point, measured in 2012, was consistently over-predicted by every model structure. This suggests that all our model structures are still failing to represent some key process related to SOC decomposition.
The use of the radiocarbon bomb peak to constrain SOC turnover models, although in use for decades (Trumbore, 1989), has often raised similar controversies. The implicit inclusion of ${ }^{14} \mathrm{C}$ data in $\mathrm{C}$ models through mass balance functions produced discrepancies between modeled and measured values in a recent study by Shirato et al. (2013). In another study (Rethemeyer et al., 2007) this approach was judged as a viable option. The explicit consideration of ${ }^{14} \mathrm{C}$ pools did not offer in this sense any advantage over implicit models. Braakhekke et al. (2014), using a soil profile model, found that the addition of $\mathrm{SO}^{14} \mathrm{C}$ data as a new constraint produced an increase in the uncertainty of the SOC stocks in the individual layers, while improved just marginally the total SOC stock estimate. Ahrens et al. (2014) utilized SO ${ }^{14} \mathrm{C}$ data to constrain an isotopically explicit single layer model in a situation where data about SOC kinetics were scarce. In that case the problem of model initialization was partially solved with additional information coming from ${ }^{14} \mathrm{C}$, but the high uncertainty of the considered system did not make it possible to determine if one site was losing or gaining carbon, and the strong interaction between MRT and deviation from the steady state made evident a trade-off between estimates with and without using $\mathrm{SO}^{14} \mathrm{C}$ data. 

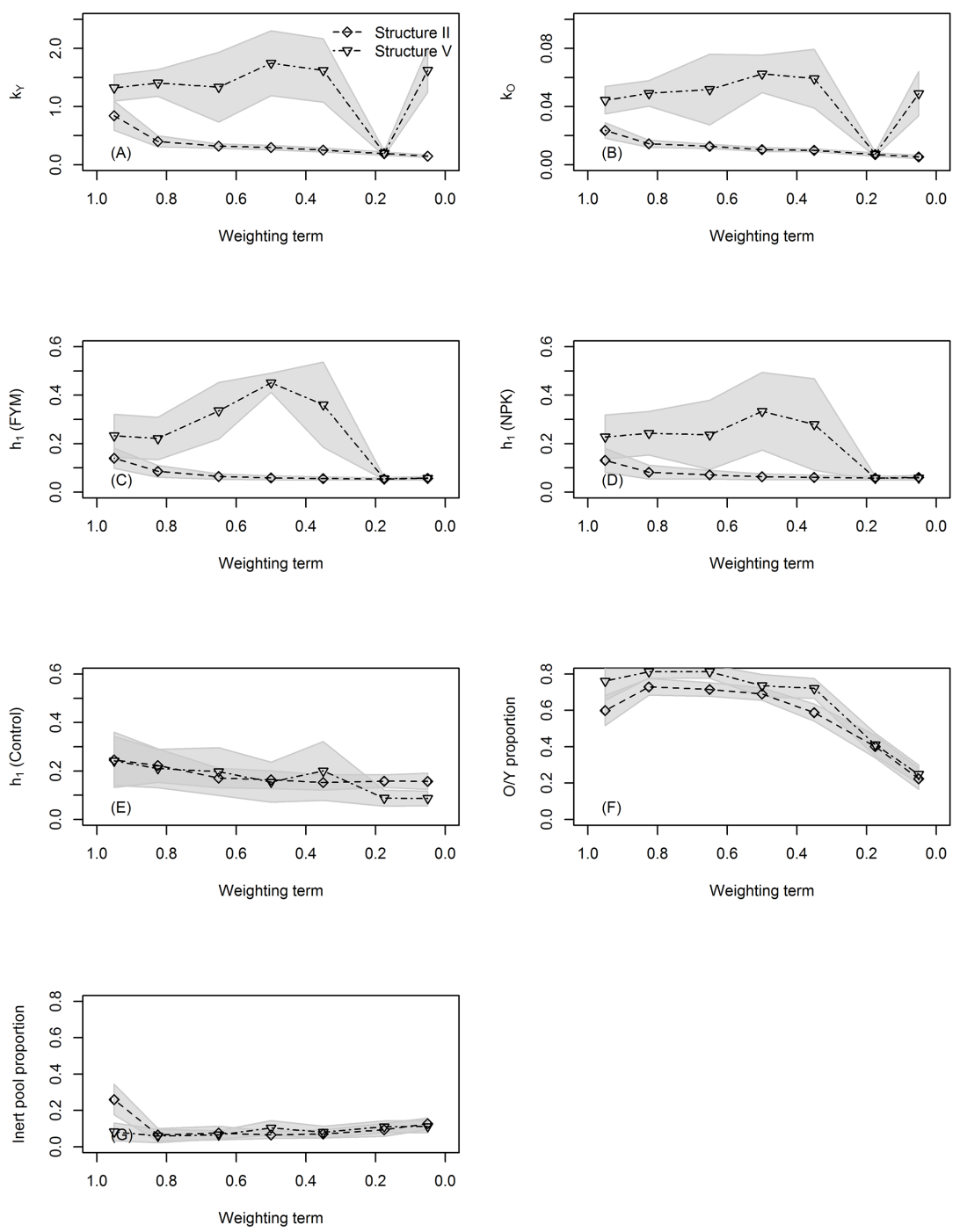

Figure 5. Effect of the $\mathrm{SO}^{14} \mathrm{C}$ data over the main SOC parameters in structure II and V. In this scale 1 means only total C, 0 means only $\mathrm{SO}^{14} \mathrm{C}$. Letters A to $\mathrm{G}$ denote subpanels referring to different parameters. The shaded areas represent the error of the calibrated parameter (calculated as standard deviation of the whole Markov chain).

One of the possible reasons for the recorded discrepancies in the estimates from models conditioned with and without $\mathrm{SO}^{14} \mathrm{C}$ data might be the absence of microbial dynamics in SOC stabilization (Riley et al., 2014). Ahrens et al. (2015), with a rather mechanistic model, recently suggested that a control on biologically mediated depolymerization can explain alone some of the observed discrepancies. But the performances of structure IV and V on our data set, lower in terms of AIC compared to the simpler structures I and II, did not allow us to confirm such a hypothesis. Another possible explanation for the discrepancy between models and measurements is the presence of recalcitrant and old organic carbon not well captured by our model structures. Structure II was selected by the $A I C$, while structure III, although not performing best with $A I C$ due to the high number of pa- rameters, presented a good RMSE. Compared to the basic structure I, both these structures introduced an additional slow SOC pool. Some form of chemical recalcitrance cannot therefore yet be ruled out.

In our study we focused on the optimal utilization of the information contained in $\mathrm{SO}^{14} \mathrm{C}$ data together with the minimization of model complexity. We found a relevant improvement of the overall model performances when also $\mathrm{SO}^{14} \mathrm{C}$ data were introduced but only until an optimal weight, while beyond that weight model performances decreased substantially. It is difficult to generalize our optimum as a general recommendation since it also depends on the density of the two data streams, but our results suggest that the relative weight of the two measurements is an additional parameter 

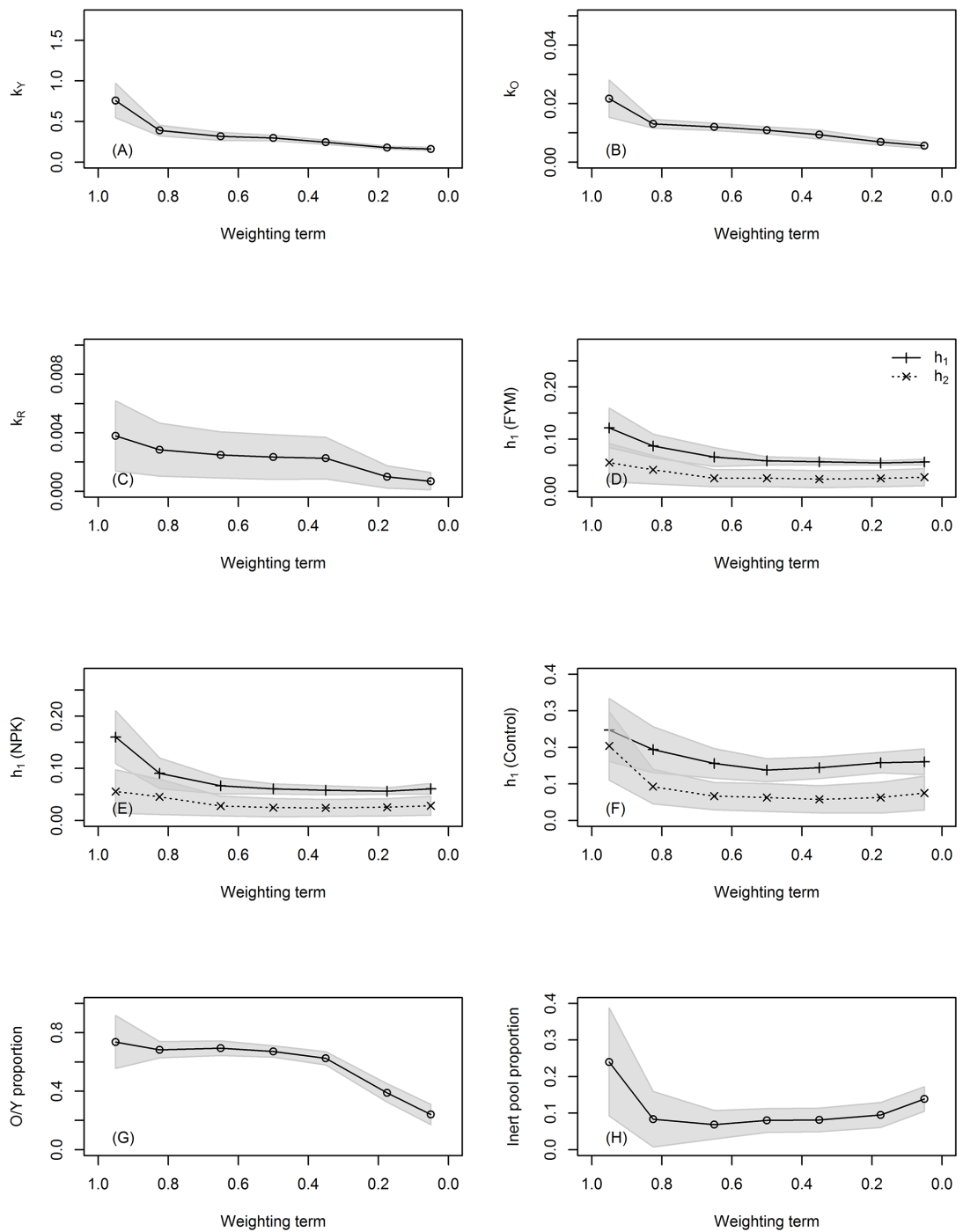

Figure 6. Effect of the $\mathrm{SO}^{14} \mathrm{C}$ data over the main SOC parameters in structure III. In this scale 1 means only total C, 0 means only $\mathrm{SO}^{14} \mathrm{C}$. The shaded areas represent the error of the calibrated parameter (calculated as standard deviation of the whole Markov chain).

that must be considered and optimized whenever the $\mathrm{SO}^{14} \mathrm{C}$ data are used for model constraining.

A generalizable and detailed mechanistic understanding of SOC stabilization is not yet available, and SOC models are still facing a deep parametrical and structural uncertainty. According to some authors (e.g., Beven, 2002) such uncertainty is inherent to the nature of ecosystem modeling, and needs to be accepted and considered in developing new methodologies. In this perspective we adopted a pragmatic approach to determine the optimal weighting factor, which turned out to be a crucial step with a large impact on modeling results.

\subsection{SOC dynamics in the ZOFE experiment as estimated by different model structures}

All the model structures indicated a rapid decrease in the young pool following the conversion from grassland to cropland. This means that the annual inputs under the new management were too small to replenish the $\mathrm{C}$ in the former young pool while most of the material is either decomposed or humified in the old pool. This is not unlikely since also by-products, like straw, are removed, and the inputs from the cropland management are greatly reduced compared to a low-intensity grassland (Rumpel et al., 2015), where a lot of the net primary productivity is either retained or returned in form of excrements. Furthermore, the disruption of the soil structure that formed under permanent grassland caused by the conversion may have released and subsequently mineral- 

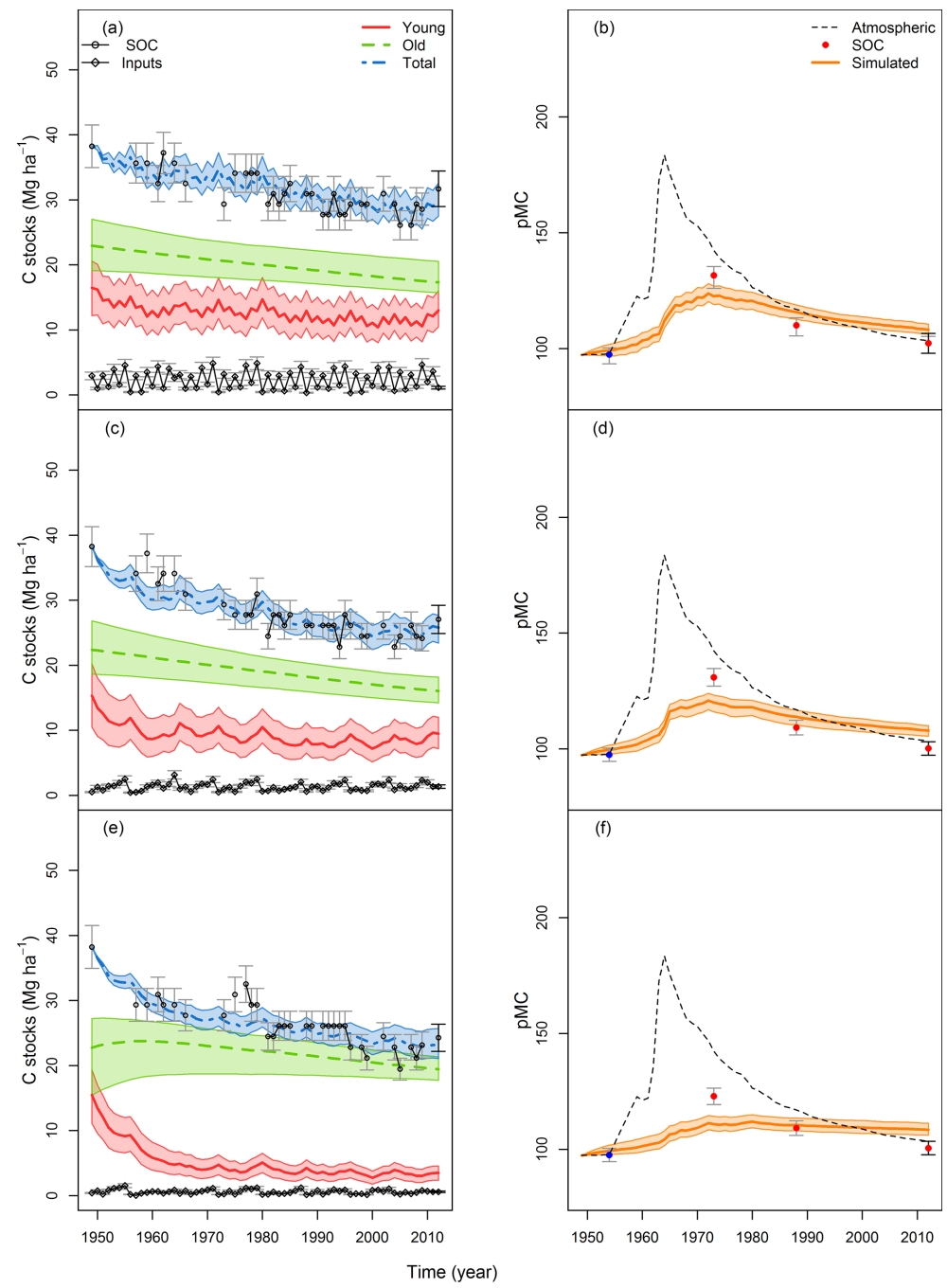

Figure 7. Simulation of SOC pools (a, c, e) and ${ }^{14} \mathrm{C}$ pools $(\mathbf{b}, \mathbf{d}, \mathbf{f})$ in the ZOFE trial as described by model structure I, with weighting factor $=0.35$, together with the measured data. Error bars represent the measured (black) and estimated (dark grey) standard error of the measurements. SOC $(\mathbf{a}, \mathbf{c}, \mathbf{e})$ is in $\mathrm{Mg} \mathrm{ha}^{-1}$, while $\mathrm{SO}^{14} \mathrm{C}(\mathbf{b}, \mathbf{d}, \mathbf{f})$ is in $\mathrm{pMC}$.

ized largely undecomposed organic matter, such as particle or light fractions previously protected inside aggregates (Six and Paustian, 2014). After this re-equilibration of the young pool, the slower but constant decrease in the total SOC was explained by all the models with a slow but constant decrease in the old pool, missing the inputs previously received from a bigger young pool. All our model structures indicated that the considered treatments in the ZOFE experiment are all still far from a new SOC equilibrium.

The error in the simulated $\mathrm{SO}^{14} \mathrm{C}$ might be due to an overestimation of the speed of the $\mathrm{C}$ cycle. Nevertheless, the fact that more complex model structures (IV, V, and III) did not present any advantage over simpler (I and II) structures makes it difficult to judge the weight of the two represented processes (stabilization of SOC, represented by an additional "inert" pool, or substrate feedbacks). The same discrepancy in predictions might also be caused by a systematic underestimation of the inputs. Except for the highest input treatment (FYM), the posterior probability distribution for the assumed input error term (Fig. S4) was always skewed toward the upper limit. This suggests some kind of systematic error concentrated in the lower end of the input range. Hence, the application of linear allometric functions to estimate carbon inputs from yields, as adopted here, must be treated with caution. The relatively symmetric distribution (and in general lower value) of the input error term for the FYM treatment in structures I, II, and III points out that model structures not considering substrate interactions might be more robust in cases of input uncertainty.

Another possible reason for the error in model predictions might be the nature of the error in the $\mathrm{SO}^{14} \mathrm{C}$ series. This has been estimated by Leifeld and Mayer (2015) from the last 

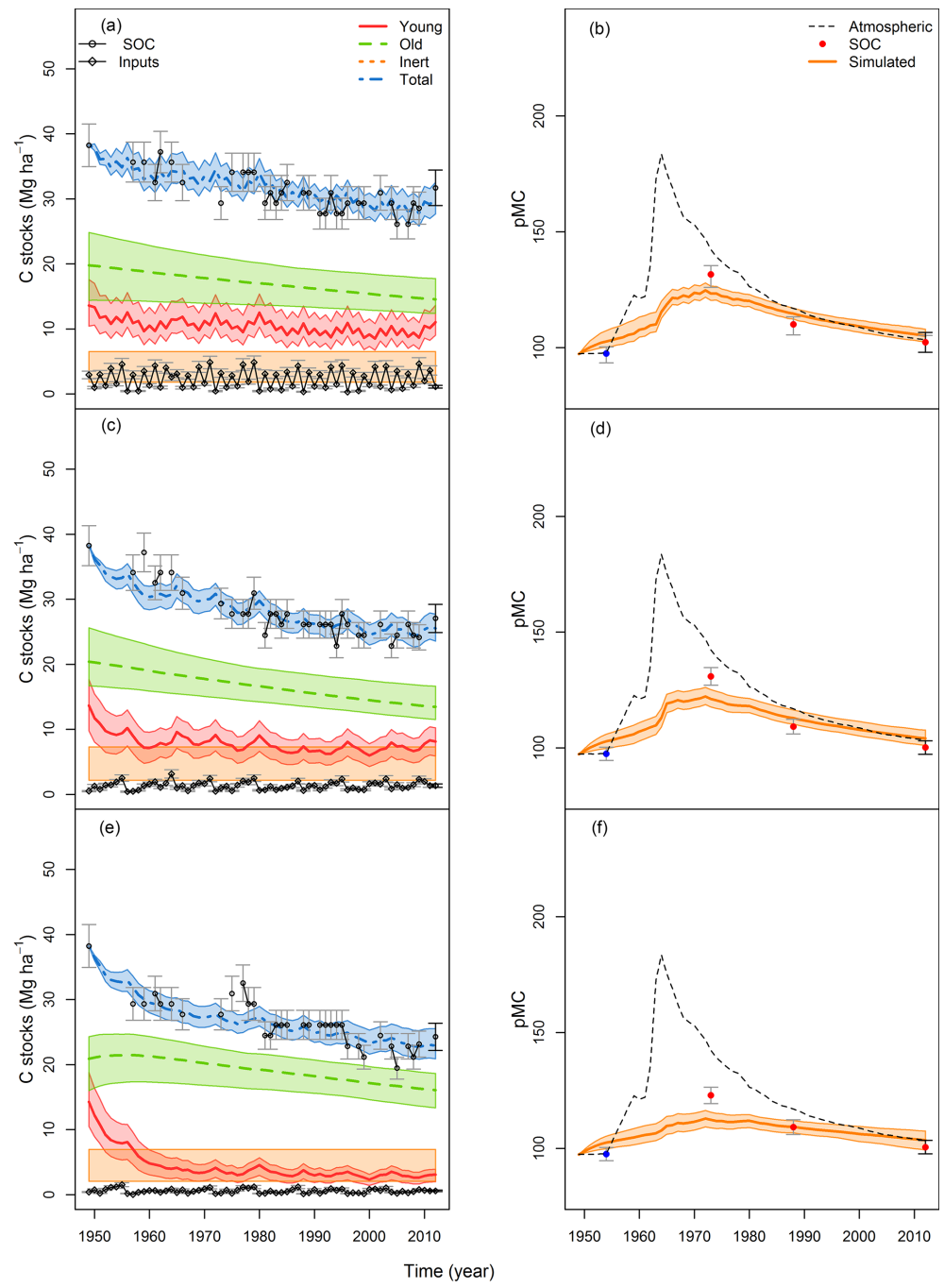

Figure 8. Simulation of SOC pools $(\mathbf{a}, \mathbf{c}, \mathbf{e})$ and ${ }^{14} \mathrm{C}$ pools $(\mathbf{b}, \mathbf{d}, \mathbf{f})$ in the ZOFE trial as described by model structure II, with weighting factor $=0.35$, together with the measured data. Error bars represent the measured (black) and estimated (dark grey) standard error of the measurements. SOC $(\mathbf{a}, \mathbf{c}, \mathbf{e})$ is in $\mathrm{Mgha}^{-1}$, while $\mathrm{SO}^{14} \mathrm{C}(\mathbf{b}, \mathbf{d}, \mathbf{f})$ is in $\mathrm{pMC}$.

time point and subsequently extrapolated to the whole time series, assuming therefore normality and homoscedasticity over time. These assumptions might not always hold in soil systems, and this would be particularly crucial in the case of the 1973 point in the control treatment. Further investigation, focused in particular to the belowground production in the ZOFE experiment, is needed for determining the reasons for such error.

\subsection{Initial SOC distribution and MRT of SOC pools in the ZOFE experiment as estimated by different model structures}

Our results for the kinetic parameters are in general in the same order of magnitude as what was reported in the literature (Andrén and Kätterer, 1997), although the introduction of the $\mathrm{SO}^{14} \mathrm{C}$ forced a deceleration of the $\mathrm{C}$ cycle.
The estimation of MRT strongly depends on all the assumptions in the model structure, and the high uncertainty around what might be the "best" structure is pointed out by the disagreement of the different criteria used for selection, which highlights the fact that there is no true model (or that "all models are wrong", Box, 1976). The combination of several structures, although difficult to perform in practice (Refsgaard et al., 2006), might therefore represent a reasonable option and deserves further attention.

The MRT estimates (Fig. 3) depend on the introduction of a substrate control term in the model structure, but once this was accounted for it seemed quite robust. We must consider here that the introduction of a substrate control term as described by Eq. (8) modifies the definition of the decomposition constants, and therefore the MRT calculated accordingly. When introducing also the term $\alpha$ in the calculation of 


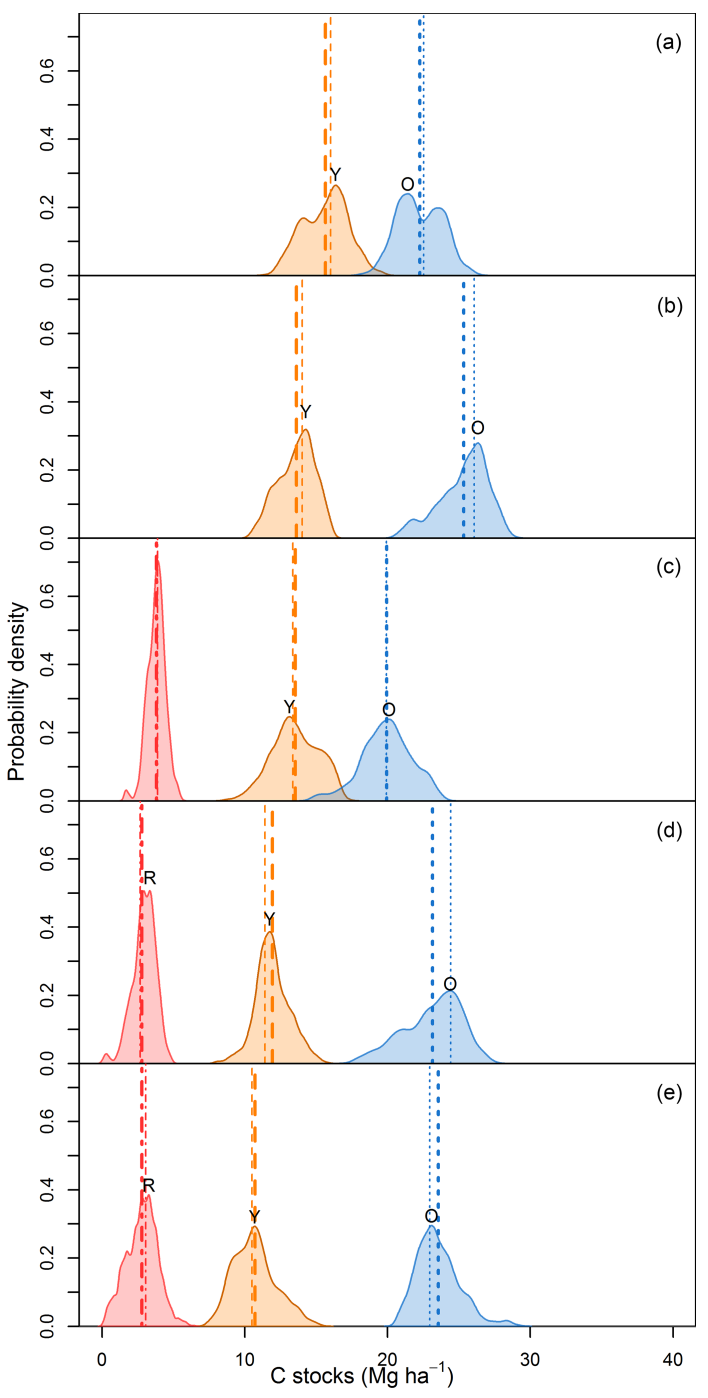

Figure 9. Probability distribution of the initial size of the $\mathrm{C}$ pools (Y: Young, O: Old, R: Recalcitrant) in structure I (a), IV (b), II (c), IV (d), V (e), with weighting factor $=0.35$. On the vertical axis the probability density of the parameter (dimensionless) is depicted and on the horizontal axis the value of the parameter (in $\mathrm{Mg} \mathrm{ha}^{-1}$ ). Vertical lines are representing the mean value (thick lines) and the Venter estimated mode (thin lines) of the Markov chains.

MRT this ranged between 2.8 and 3.1 and 46.0 and 54.5 years for young and old pool, respectively, so not far from what indicated by the other structures. A detailed discussion about the MRT definition is outside the scope of this study, but here we want to make clear that a direct comparison of the MRT between these two groups of structures according to a common definition would not be meaningful and the differences in the model structure must be accounted for.

Model initialization seemed quite robust, with values substantially not differing between models with the same number of pools.

\subsection{Balancing the bias/variance dilemma in SOC modeling}

As suggested by the multiple structures evaluated in this study, the conceptual nature of SOC pools makes their definition volatile. Each pool is a theoretical construction defined specifically by assumptions at the level of model structure as well as model calibration.

Some attempts have been made to reconcile a definition of $\mathrm{C}$ pools with real measurements. For example the wellestablished forest model Yasso (Liski et al., 2005) bases its calibration on data from chemical litter fractionation, which gives the initialization values for the different $C$ pools. But the fractionation behind Yasso might seem questionable in agricultural soils where inputs are often homogenized with the mineral fraction and less, if at all, identifiable. In more homogenized mineral topsoils the main obstacle to this approach is that available fractionation methods do not reflect precise stabilization processes (von Lützowet al., 2007). One of the most promising recent attempts to develop a non-theoretical quantification of SOC pools in agricultural/mineral soils is the one by Zimmermann et al. (2007), which tried to develop a measurement standard for RothC (Coleman et al., 1997) pools. All these methods share in common the risk that correlations between the measurements and the theoretical pools might be strongly localized (or difficult to reproduce, Poeplau et al., 2013). This is not surprising given the complexity of SOC stabilization mechanisms (Kleber et al., 2011). Indications are that stability should be considered as an intrinsic property of the soil ecosystem (Schmidt et al., 2011) and thus local. It is therefore problematic to generalize a fractionation methodology that reflects in detail SOC stabilization processes, which would in turn define SOC pools.

Hence, we still need to aggregate the available information in a theory of SOC decomposition that is simple enough to be generalizable. This way the model structure represents the SOC decomposition processes in an aggregated (and simplified) way that is compatible with the amount of knowledge at disposal. The challenge of conciliating predictive power, and therefore practical value of our models, with accuracy is the formulation of the bias/variance trade-off as found in modern soil science.

As suggested from our data set, which although not perfect is already relatively rich in information and not far from the best possible conditions available for soil carbon modeling, the information available for inverse modeling discrimination still seems insufficient to validate models that are too mechanistic. A possible improvement could be the inclusion of data from deep soil layers, and the extension of the model to represent spatial processes. In general, we would expect a better resolving power of the data by adding new constrains to the model, although this would be also dependent on the additional assumptions needed to include another dimension. 
Testing this approach was however out of the scope of the present study, but foreseeable in the near future.

\section{Conclusions}

The SOC in the ZOFE experiment underwent a profound decrease after the initial land use change from grass- to cropland. This decrease was described in the first years by all our model structures as a fast re-equilibration of the young pool, which decreased rapidly after a reduction of the inputs and/or an increased mineralization and caused in consequence a slower but constant decrease in the older pools. In the long term, treatments not receiving organic fertilization were still losing $\mathrm{C}$ even more than 60 years after land use change. The estimates of the MRT in the ZOFE experiment were robust once accounted for differences inherent to the model structures. Comparable model structures (in particular I, II, and III) were relatively in agreement, and the influence of the number of pools on MRT was instead quite limited.

The introduction of $\mathrm{SO}^{14} \mathrm{C}$ data during calibration improved performances of all model structures and reduced the uncertainty of the parametrization. It also made clear the existence of a trade-off between representing the information from $\mathrm{SO}^{14} \mathrm{C}$ and SOC when utilizing a multi-pool SOC model structure. None of our five structures seemed able to reconcile consistently the two data streams. This suggests the presence of processes that were implicit in the $\mathrm{SO}^{14} \mathrm{C}$ data stream but not well described in our model structures, which caused the information from the $\mathrm{SO}^{14} \mathrm{C}$ to have a strong impact on the results. We therefore suggest the explicit consideration of a weight associated with each data stream as a routine procedure whenever $\mathrm{SO}^{14} \mathrm{C}$ data are considered as an additional model constrain.

In our data set, the best model performances were achieved by the two simpler models, pointing out that the data available do not allow for a more detailed mechanistic SOC modeling. Although processes based on interactions of part of the substrate with the decomposition kinetics might explain the observations, recalcitrance inherent to the substrate (corresponding to the adoption of a slower additional decomposing $\mathrm{C}$ pool) remains a valid alternative in explaining the data.

\section{Data availability}

All the data on which this study is based are published in previous studies and the sources are cited in the text.

\section{The Supplement related to this article is available online at doi:10.5194/bg-13-3003-2016-supplement.}

\section{References}

Ågren, G., Bosatta, E., and Balesdent, J.: Isotope discrimination during decomposition of organic matter: a theoretical analysis, Soil Sci. Soc. Am. J., 60, 1121-1126, 1996.

Ahrens, B., Reichstein, M., Borken, W., Muhr, J., Trumbore, S. E., and Wutzler, T.: Bayesian calibration of a soil organic carbon model using $\Delta^{14} \mathrm{C}$ measurements of soil organic carbon and heterotrophic respiration as joint constraints, Biogeosciences, 11, 2147-2168, doi:10.5194/bg-11-2147-2014, 2014.

Ahrens, B., Braakhekke, M. C., Guggenberger, G., Schrumpf, M., and Reichstein, M.: Contribution of sorption, DOC transport and microbial interactions to the ${ }^{14} \mathrm{C}$ age of a soil organic carbon profile: Insights from a calibrated process model, Soil Biol. Biochem., 88, 390-402, 2015.

Akaike, H.: A new look at the statistical model identification, Transactions on Automatic Control, 19, 716-723, 1974.

Alexander, P., Paustian, K., Smith, P., and Moran, D.: The economics of soil $\mathrm{C}$ sequestration and agricultural emissions abatement, SOIL, 1, 331-339, doi:10.5194/soil-1-331-2015, 2015.

Andrén, O. and Kätterer, T.: ICBM: The Introductory Carbon Balance Model for Exploration of Soil Carbon Balances, Ecol. Appl., 7, 1226-1236, 1997.

Andrén, O., Kätterer, T., Juston, J., Waswa, B., and De Nowina, K. R.: Soil carbon dynamics, climate, crops and soil type - calculations using introductory carbon balance model (ICBM) and agricultural field trial data from sub-Saharan Africa, Afr. J. Agric. Res., 7, 5800-5809, 2012.

Bauer, J., Herbst, M., Huisman, J., Weihermüller, L., and Vereecken, H.: Sensitivity of simulated soil heterotrophic respiration to temperature and moisture reduction functions, Geoderma, 145, 17-27, 2008.

Beven, K.: Towards a coherent philosophy for modelling the environment, Proc. Roy. Soc. A, 458, 2465-2484, 2002.

Beven, K.: A manifesto for the equifinality thesis, J. Hydrol., 320, 18-36, 2006.

Beven, K. J.: Environmental Modelling: An Uncertain Future?, London, Routledge, 2008.

Bolinder, M. A., Janzen, H. H., Gregorich, E. G., Angers, D. A., and Van den Bygaart, A. J.: An approach for estimating net primary productivity and annual carbon inputs to soil for common agricultural crops in Canada, Agr. Ecosyst. Environ., 118, 29-42, 2007.

Bond-Lamberty, B., Wang, C., and Gower, S. T.: Aboveground and belowground biomass and sapwood area allometric equations for six boreal tree species of northern Manitoba, Can. J. Forest Res., 32, 1441-1450, 2002.

Bosatta, E. and Ågren, G.: Soil organic matter quality interpreted thermodynamically, Soil Biol. Biochem., 31, 1889-1891, 1999.

Box, G. E. P.: Science and Statistics, J. Am. Stat. Assoc., 71, 791799, 1976.

Braakhekke, M. C., Beer, C., Schrumpf, M., Ekici, A., Ahrens, B., Hoosbeek, M. R., Kruijt, B., Kabat, P., and Reichstein, M.: The use of radiocarbon to constrain current and future soil organic matter turnover and transport in a temperate forest, J. Geophys. Res.-Biogeo., 119, 372-391, 2014.

Briscoe, E. and Feldman, J.: Conceptual complexity and the bias/variance tradeoff, Cognition, 118, 2-16, 2011.

Edited by: A. Ito 
Brooks, S. P. B. and Gelman, A. G.: General methods for monitoring convergence of iterative simulations, J. Comput. Graph. Stat., 7, 434-455, 1998.

Burnham, K. P. and Anderson, D. R.: Multimodel Inference: Understanding AIC and BIC in Model Selection, Sociol. Method. Res., 33, 261-304, 2004.

Coleman, K., Jenkinson, D., and Crocker, G.: Simulating trends in soil organic carbon in long-term experiments using RothC-26.3, Geoderma, 81, 29-44, 1997.

Francey, R., Allison, C., Etheridge, D., Trudinger, C., Enting, I., Leuenberg, M., Lagenfelds, R.,Michel, E., and Steele, L.: A 1000 -year high precision record of $\delta^{13} \mathrm{C}$ in atmospheric $\mathrm{CO}_{2}$, Tellus B, 51, 170-193, 1999.

Goslar, T., Van Der Knaap, W., Hicks, S., Andric, M., Czernik, J., Goslar, E., Räsänen, S., and Hyötylä, H.: Radiocarbon dating of modern peat profiles: pre- and post-bomb $\mathrm{C}$ variations in the construction of age-depth models, Radiocarbon, 46, 1111-1150, 2004.

IPCC: Climate Change 2014: Impacts, Adaptation, and Vulnerability, Part A: Global and Sectoral Aspects, Contribution of Working Group II to the Fifth Assessment Report of the Intergovernmental Panel on Climate Change, edited by: Field, C. B., Barros, V. R., Dokken, D. J., Mach, K. J., Mastrandrea, M. D., Bilir, T. E., Chatterjee, M., Ebi, K. L., Estrada, Y. O., Genova, R. C., Girma, B., Kissel, E. S., Levy, A. N., MacCracken, S., Mastrandrea, P. R., and White, L. L., Cambridge, United Kingdom and New York, NY, USA, Cambridge University Press, 2014.

Juston, J.: Environmental Modelling: Learning from Uncertainty, TRITA LWR PHD 1068, 2012

Kätterer, T., Andrén, O., and Persson, J.: The impact of altered management on long-term agricultural soil carbon stocks - a Swedish case study, Nutr. Cycl. Agroecosys., 70, 179-188, 2004.

Kätterer, T., Bolinder, M., Andrén, O., Kirchmann, H., and Menichetti, L.: Roots contribute more to refractory soil organic matter than aboveground crop residues, as revealed by a longterm field experiment, Agr. Ecosyst. Environ., 141, 184-192, 2011.

Kleber, M., Nico, P. S., Plante, A., Filley, T., Kramer, M., Swanston, C., and Sollins, P.: Old and stable soil organic matter is not necessarily chemically recalcitrant: implications for modelling concepts and temperature sensitivity, Glob. Change Biol., 17, 10971107, 2011.

Kurths, J., Schwarz, U., Sonett, C. P., and Parlitz, U.: Testing for nonlinearity in radiocarbon data, Nonlinear Proc. Geoph., 1, 7276, 1994.

Kuzyakov, Y. and Gavrichkova, O.: Time lag between photosynthesis and carbon dioxide efflux from soil: A review of mechanisms and controls, Glob. Change Biol., 16, 3386-3406, 2010.

Lal, R.: Soil carbon sequestration to mitigate climate change, Geoderma, 123, 1-22, 2004

Leifeld, J.: Biased ${ }^{14} \mathrm{C}$-derived organic carbon turnover estimates following black carbon input to soil: an exploration with RothC, Biogeochemistry, 88, 205-211, 2008.

Leifeld, J. and Mayer, J.: ${ }^{14} \mathrm{C}$ in cropland soil of a long-term field trial - experimental variability and implications for estimating carbon turnover, SOIL, 1, 537-542, doi:10.5194/soil-1-537$2015,2015$.
Levin, I. and Kromer, B.: The tropospheric ${ }^{14} \mathrm{CO}_{2}$ level in midlatitudes of the Northern Hemisphere (1959-2003), Radiocarbon, 46, 1261-1272, 2004.

Levin, I., Kromer, B., and Hammer, S.: Atmospheric $\Delta^{14} \mathrm{CO}_{2}$ trend in Western European background air from 2000 to 2012, Tellus B 2013, 65, 20092, 2013

Liski, J., Palosuo, T., Peltoniemi, M., and Sievänen, R.: Carbon and decomposition model Yasso for forest soils, Ecol. Model., 189, 168-182, 2005.

Oberholzer, H. R., Leifeld, J., and Mayer, J.: Changes in soil carbon and crop yield over 60 years in the Zürich Organic Fertilization Experiment, following land-use change from grassland to cropland, J. Plant Nutr. Soil Sc., 493, 696-704, 2014.

Parton, B., Ojima, D., Del Grosso, S., and Keough, C.: CENTURY Tutorial, Supplement to CENTURY User's Manual, 2001.

Parton, W. J., Scurlock, J. M. O., Ojima, D. S., Gilmanov, T. G., Scholes, R. J., Schimel, D. S., Kirchner, T., Menaut, J.-C., Seastedt T., Garcia Moya, E. G., Kamnalrut, A., and Kinyamario, J. I.: Observations and modeling of biomass and soil organic matter dynamics for the grassland biome worldwide, Global Biogeochem. Cy., 7, 785-809, 1993.

Plummer, M.: JAGS: A Program for Analysis of Bayesian Graphical Models Using Gibbs Sampling JAGS: Just Another Gibbs Sampler, in: Proceedings of the 3rd International Workshop on Distributed Statistical Computing, edited by: Hornik, K., Leisch, F., and Zeileis, A., Vienna, 2003.

Plummer, M.: Penalized loss functions for Bayesian model comparison, Biostatistics, 9, 523-539, 2008.

Poeplau, C., Don, A., Dondini, M., Leifeld, J., Nemo, R., Schumacher, J., Senapati, N., and Wiesmeier, M.: Reproducibility of a soil organic carbon fractionation method to derive RothC carbon pools, Eur. J. Soil Sci., 64, 735-746, 2013.

Primault, B.: Du calcul de l'évapotranspiration, Arch. Met. Geoph. Biocl. Ser. B, 12, 124-150, 1962.

Refsgaard, J. C., van der Sluijs, J. P., Brown, J., and van der Keur, P.: A framework for dealing with uncertainty due to model structure error, Adv. Water Resour., 29, 1586-1597, 2006.

Rethemeyer, J., Grootes, P. M., Brodowski, S., and Ludwig, B.: Evaluation of soil ${ }^{14} \mathrm{C}$ data for estimating inert organic matter in the RothC model, Radiocarbon, 49, 1079-1091, 2007.

Riley, W. J., Maggi, F., Kleber, M., Torn, M. S., Tang, J. Y., Dwivedi, D., and Guerry, N.: Long residence times of rapidly decomposable soil organic matter: application of a multi-phase, multi-component, and vertically resolved model (BAMS1) to soil carbon dynamics, Geosci. Model Dev., 7, 1335-1355, doi:10.5194/gmd-7-1335-2014, 2014.

Rumpel, C., Crème, A., Ngo, P. T., Velásquez, G., Mora, M. L., and Chabbi, A.: The impact of grassland management on biogeochemical cycles involving carbon, nitrogen and phosphorus, J. Soil Sci. Plant Nutr., 15, 353-371, 2015.

Schimel, J. and Weintraub, M.: The implications of exoenzyme activity on microbial carbon and nitrogen limitation in soil: a theoretical model, Soil Biol. Biochem., 35, 549-563, 2003.

Schmidt, M., Torn, M., Abiven, S., Dittmar, T., Guggenberger, G., Janssens, I., Kleber, M., Kögel-Knabner, I., Lehmann, J., Manning, D., Nannipieri, P., Rasse, D., Weiner, S., and Trumbore, S.: Persistence of soil organic matter as an ecosystem property, Nature, 478, 49-56, 2011. 
Shirato, Y., Jomura, M., Wagai, R., Kondo, M., Tanabe, K., and Uchida, M.: Deviations between observed and RothC-simulated $\Delta^{14} \mathrm{C}$ values despite improved IOM initialization, Eur. J. Soil Sci., 64, 576-585, 2013.

Six, J. and Paustian, K.: Aggregate-associated soil organic matter as an ecosystem property and a measurement tool, Soil Biol. Biochem., 68, A4-A9, 2014.

Stuiver, M. and Polach, H.: Reporting of ${ }^{14} \mathrm{C}$ Data, Radiocarbon, 19, 355-363, 1977.

Trumbore, S.: AMS ${ }^{14} \mathrm{C}$ measurements of fractionated soil organicmatter-an approach to deciphering the soil carbon-cycle, Radiocarbon, 31, 644-654, 1989.

Trumbore, S. E. and Czimczik, C. I.: An uncertain future for soil carbon, Science, 321, 1455-1456, 2008.

Tsai, W.-C. and Hu, W.-P.: Theoretical analysis on the kinetic isotope effects of bimolecular nucleophilic substitution $\mathrm{S}_{N} 2$ reactions and their temperature dependence, Molecules, 18, 4816-43, 2013. von Lützow, M., Kögel-Knabner, I., Ekschmitt, K., Flessa, H., Guggenberger, G., Matzner, E., and Marschner, B.: SOM fractionation methods: Relevance to functional pools and to stabilization mechanisms, Soil Biol. Biochem., 39, 2183-2207, 2007.

Walther, U., Menzi, H., Ryser, J.-P., Flisch, R., Jeangros, B., Kessler, W., Maillard, A., Siegenthaler, A. F., and Vuilloud, P. A.: Grund-lagen für die Düngung im Acker- und Futterbau, Agrarforschung, 1, 1-40, 1994.

WRB: World Reference Base for Soil Resources 2006, first update 2007, World Soil Resources Reports No. 103, FAO, Rome, 2007.

Wutzler, T. and Reichstein, M.: Priming and substrate quality interactions in soil organic matter models, Biogeosciences, 10, 20892103, doi:10.5194/bg-10-2089-2013, 2013.

Zimmermann, M., Leifeld, J., Schmidt, M. W. I., Smith, P., and Fuhrer, J.: Measured soil organic matter fractions can be related to pools in the RothC model, Eur. J. Soil Sci., 58, 658-667, 2007. 